\title{
FATTY ACID AND TRIACYLGLYCEROL COMPOSITIONS OF MILK THISTLE SEEDS GROWING WILD IN TUNISIA (SILYBUM MARIANUM L.)
}

\author{
S. Harrabi ${ }^{a *}$, H. Romdhane ${ }^{b}$, M. DaAssa ${ }^{b}$ and H. Fellah ${ }^{a}$

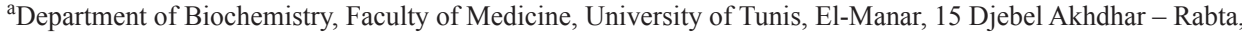 \\ 1007 Bab Saâdoun. Tunisia \\ ${ }^{\mathrm{b}}$ Laboratory of oil analysis, Sousse. Tunisia
}

(Received: 18 December 2013; accepted: 1 February 2014)

\begin{abstract}
The milk thistle plant grows in many regions in Tunisia; however, there is no literature regarding their oil composition. In this study, oil content, fatty acids and triacylglycerols compositions of milk thistle seeds growing wild in Tunisia were determined. The oil content was $30.5 \%$, thus milk thistle seeds could be exploited as natural new source of oil. Among the fatty acids, linoleic acid had the highest percentage (59.98\%) followed by oleic acid $(21.26 \%)$ and palmitic acid (12.74\%). The extracted oil from milk thistle seeds is rich in polyunsaturated fatty acids $(60.37 \%)$. Various molecular species of TAGs were detected and the major forms were LLL (22.30\%), OLL (20.40\%), PLL $(17.31 \%)$, POL $(14.30 \%)$, and OOL $(7.90 \%)$. It can be concluded that milk thistle seed oil has a characteristic TAG pattern as compared with these elucidated for olive oil and soybean oil.

Keywords: Silybum marianum, seeds, oil content, fatty acids, triglycerides
\end{abstract}

The milk thistle plant, Silybum marianum (family: Asteraceae) is an annual or biennial plant, native to the Mediterranean region and some parts of the United States, which has now spread to other warm and dry regions (HADOLIN et al., 2001). This plant grows wild in many regions in Tunisia. Seeds of milk thistle have been used for more than 2000 years to treat liver diseases (KARKANIS et al., 2011). This seed contains silymarin, a mixture of flavonolignans of which silybin is the main compound, and oil (HADOLIN et al., 2001; KHAN et al., 2007). The oil has to be removed from seeds prior to the extraction of silymarin. So it is a by-product of silymarin production (HADOLIN et al., 2001).

The fatty acid composition of vegetable oils varies depending on plant origin, genetic factors, ripening grade of fruit, and specific climatic conditions (Velasco et al., 2005). Because the apparent relationship between the amounts or types of fatty acids consumed and the incidence of some disease has been noted, knowledge of the composition of edible fats has been considered to be essential (KINSELLA, 1986). RủŽǏ̌KOVÁ and co-workers (2011) have reported the fatty acids composition of the milk thistle oil samples from Serbia and Czech Republic, polyunsaturated fatty acids ranged from $50.81 \%$ to $66.66 \%, 17.88-27.04 \%$ of unsaturated fatty acids and $15.44-22.14 \%$ of saturated fatty acids. Still in the literature there is a lack of the individual fatty acid profiles in the different genotypes of milk thistle of the globe (RƯŽǏČKOVÁ et al., 2011).

Triacylglycerols (TAGs) are the main constituents (95-98\%) of plant oils and animal fats. They contain three fatty acid molecules esterified to the three hydroxyl groups of

* To whom correspondence should be addressed.

Phone: + 21697505156; fax: +21671563715; e-mail: sawsemtahar@yahoo.fr

0139-3006/\$20.00 @ 2015 Akadémiai Kiadó, Budapest 
glycerol. Triglyceride composition has been established as a measurement of the quality and purity of vegetable oils and it is used increasingly in the food industry to confirm authenticity. Various forms of TAGs are separated and identified from many vegetable oils and there are a number of notable differences in TAG composition among species (RĚZANKA \& RĚZANKOVÁ, 1999). The triacylglycerol composition of milk thistle seed oil was reviewed by a few researchers (El-MALLAH et al., 2003; HoLČAPEK et al., 2003; ANDRIKOPOULOS et al., 2004). No data are available on the triacylglycerol composition of the milk thistle from Tunisia.

The fatty acid pattern of milk thistle seeds has been performed in Egypt (EL-MaLlaH et al., 2003), Pakistan (Khan et al., 2007), and Iran (Hasanloo et al., 2008; FATHI-ACHACHLOUEI \& AZADMARD-DAMIRChi, 2009). To the best of our knowledge, no literature was reported about the fatty acid and triglyceride compositions of milk thistle seeds grown in Tunisia. The aim of the present study was to determine total lipid content, fatty acid composition, and TAG pattern of milk thistle seeds grown in Tunisia. The data obtained is important locally and internationally in evaluating the potential of milk thistle seeds to be exploited as a new source of oil for nutritional, industrial, and pharmaceutical applications.

\section{Materials and methods}

\subsection{Plant materials}

Milk thistle seeds were collected from plants grown wild in Tunisia (Sousse region) at the end of June 2012. Hundred grams of seeds were dried and then grounded to fine powder in a grinder.

\subsection{Oil extraction}

The oils were extracted using petroleum ether in Soxhlet extractors for $4 \mathrm{~h}$. The solvent was removed with a rotary evaporator at $40{ }^{\circ} \mathrm{C}$. Oil samples were placed at ambient temperature (25-35 $\left.{ }^{\circ} \mathrm{C}\right)$.

\subsection{Analysis of fatty acids by gas-liquid chromatography}

The fatty acid composition of the seed oil was determined by gas chromatography (GC) according to IOC method of analysis (2001). Fatty acid methyl esters were prepared by simultaneous extraction and methylation following the procedure described by METCALFE and coworkers (1966) and modified by LECHEVALLIER (1966). Fatty acid methyl esters were analysed by GC using a HP 6890 chromatograph equipped with a flame ionisation detector (FID) on a capillary column, CP-Sil 88 (50 m length, $0.25 \mathrm{~mm}$ id, $0.2 \mu \mathrm{m}$ film thickness; Varian). Column temperature was programmed from 150 to $200{ }^{\circ} \mathrm{C}\left(4^{\circ} \mathrm{C} \mathrm{min}-1\right)$. Temperatures of detector and injector were 260 and $190^{\circ} \mathrm{C}$, respectively. The fatty acids were identified by comparison of their retention times with those of standards (palmitic, stearic, heptadecanoic, oleic, linolenic, arachidic, gadoleic, and lignoceric acids, all from Merck, Darmstadt, Germany). The quantitative evaluation was carried out on the base of gas chromatography peak areas of the different methyl esters. The response factor for fatty acids, calculated by using heptadecanoic methyl ester, was 0.95 . 


\subsection{Analysis of triacylglycerols by high performance liquid chromatography (HPLC)}

Triacylglycerol (TAG) molecular species profile was elucidated according to IOC method of analysis (2008), using the RP-HPLC instrument (Agilent technology, 1200 series). A $10 \mu 1$ solution of oil in chloroform $\left(300 \mathrm{mg} \mathrm{ml}^{-1}\right)$ was injected into the Spherisorb ODS-2 column (ODS2-SB5-38236; $4.6 \mathrm{~mm} \times 250 \mathrm{~mm} ; 5 \mu \mathrm{m}$ particle size; Capital HPLC limited). Gradient elution with acetonitrile: acetone $(50: 50, \mathrm{v} / \mathrm{v})$ in 50 minutes was conducted. The flow rate was $1.5 \mathrm{ml} \mathrm{min}{ }^{-1}$ and the detection was performed with refractive index detector (G1362A, Agilent). The carbon number assignment for the separated peaks was determined using HPLC chromatogram for soybean oil taken as a reference.

\subsection{Statistical analysis}

Statistical analysis was performed by using the Proc ANOVA in SAS (Software version 8). Duncan's Multiple Range Test was used. For each oil sample, three determinations have been done.

\section{Results and discussion}

\subsection{Oil content}

The level of total lipid (expressed in $\mathrm{g} / 100 \mathrm{~g}$ of dry weight of seeds) found in the sample analysed was $30.5 \%$, which is higher than those reported previously for Pakistani samples (26.05\%) (KHAN et al., 2007) and Czech samples (17.5-21.6\%) (RưŽǏ̌KovÁ et al., 2011). These differences can be explained by the previous findings, that seed oil content in milk thistle is affected by the environment, the genotype, and the year (RỦžǏčoví et al., 2011). Additionally, MALEKZADEH and co-workers (2011) have reported that the total oil content of milk thistle seeds decreased under the drought stress. These seeds have high oil content comparable with the corn kernel (4\%) (HARRABI et al., 2009). However, the oil content is in the same order with the oil content reported for some oil-seed crops such as soybean (17$21 \%$ ), cotton seeds (15-24\%), olive (20-25\%) (MatThaus \& OzCAN, 2006). The extracted oil from milk thistle seed has been suggested as being suitable as an edible oil (HADolin et al., 2001; El-Mallah et al., 2003). This data suggested that these milk thistle seeds might potentially serve as natural new source of oil.

\subsection{Fatty acid pattern}

A literature search revealed that there is limited information on the fatty acid profile of milk thistle seeds (HASANLOO et al., 2008; RƯŽǏ̌KOvá et al., 2011). The fatty acid composition determined by GC is presented in Table 1. Linoleic acid was predominant (59.98\%) followed by oleic acid (21.26\%), palmitic acid (12.74\%), and stearic acid (3.24\%). The linoleic acid content determined was higher than that in the milk thistle cultivars grown in Baku (34\%) (GARAEV et al., 2010). RǓžIČKOVÁ and co-workers (2011) have reported the fatty acid profiles of the milk thistle samples from Serbia and Czech Republic. For all samples dominant fatty acid was linoleic (50.58-66.4\%) followed by oleic acid (16.26-25.44\%), palmitic acid (7.24-9.20\%), and stearic acid (3.56-5.92\%). Pakistani samples had also higher contents of linoleic acid (64.4\%) and oleic acid (26.38\%) (KHAN et al., 2007). However, Iranian samples showed lower content of linoleic acid (45.36\%), but higher conent of oleic acid (31.58\%) (HASANLOO et al., 2008). The fatty acid composition of the milk thistle oil was similar to the 
corn kernel oil, where linoleic acid was the most abundant fatty acid (49.7-62.7\%) followed by oleic (23.5-34.9\%) and palmitic (9.5-11.5\%) acids (HARRABI et al., 2009). Therefore, milk thistle oil can be recommended as a replacement for corn kernel oil. This contrasts with the composition of olive oil, where oleic acid was the most abundant fatty acid (GERBER, 1997; RĚZANKA \& RĚZANKOVÁ, 1999).

\begin{tabular}{lc} 
Table 1. Fatty acid composition (\%) of oil extracted from milk thistle seeds grown in Tunisia \\
\hline Fatty acids (FA) & $\%$ \\
\hline Palmitic acid C16:0 & $12.74 \pm 0.2$ \\
Palmitoleic acid C16:1 & $0.16 \pm 0.1$ \\
Stearic acid C18:0 & $3.24 \pm 0.3$ \\
Oleic acid C18:1 & $21.26 \pm 0.4$ \\
C18:1 trans & $0.01 \pm 0.0$ \\
Linoleic acid C18:2 & $59.98 \pm 0.3$ \\
C18:2 trans & $0.03 \pm 0.1$ \\
Linolenic acid C18:3 & $0.36 \pm 0.2$ \\
Arachidic acid C20:0 & $1.62 \pm 0.1$ \\
Gadoleic acid C20:1 $24: 0$ & $0.29 \pm 0.1$ \\
Lignoceric acid C24:0 & $0.31 \pm 0.1$ \\
SFA & $17.91 \pm 0.2$ \\
MUFA & $21.72 \pm 0.2$ \\
PUFA & $60.37 \pm 0.3$ \\
UFA & $82.09 \pm 0.4$ \\
\hline
\end{tabular}

SFA: total saturated FA; MUFA: total monounsaturated FA; PUFA: total polyunsaturated FA; UFA: total unsaturated FA

The total saturated fatty acids (SFA) level of milk thistle seed oil was $17.91 \%$ of total fatty acids, and was comparable to that in Iranian samples (19-21\%) (FAthi-Achachlouer \& AZADMARD-DamirCHI, 2009). The milk thistle seeds have high content of unsaturated fatty acids and therefore might serve as substitute for highly unsaturated fatty oils. The monounsaturated fatty acids (MUFA) amount was $21.72 \%$, which is close to that of soybean oil (22\%) and corn oil (26.5\%) (BAYLIN et al., 2007). These data suggest that milk thistle seeds may serve as dietary sources of special MUFA, which have been associated with lowering the risk of cardiovascular diseases (GERBER, 1997). The studied oil samples had high polyunsaturated fatty acid (PUFA) (60.37\%) and low saturated fatty acids (17.8\%) contents. This is important from a nutritional point of view, in fact PUFA are indispensable dietary components in human body and they must be ingested as part of the diet. The high content of PUFA in milk thistle oil makes it useful for therapeutic purposes in coronary heart diseases. In fact, PUFA have been suggested to be beneficial in reducing the risk of certain chronic diseases, such as coronary heart disease, stroke, and rheumatoid arthritis (CALDER, 2008). 


\subsection{Triacylglycerol pattern}

The qualitative and quantitative triacylglycerol contents can be used as markers for the detection of oil adulteration (RĚZANKa \& RĚZANKovÁ, 1999; Harrabi et al., 2008). So, it is necessary to determine the triglyceride pattern of the different vegetable oils. Various molecular species of TAGs were detected and the major forms were LLL (22.30\%), OLL (20.44\%), PLL (17.31\%), POL (14.30\%), and OOL (7.90\%) (Table 2). These five forms of TAGs are also found in Egyptian samples but at different proportions (EL-MALLAH et al., 2003). These results suggested that milk thistle oil contains a higher amount of di- and triunsaturated TAGs (PLL, LLL, OLL, etc.) vs. monounsaturated forms such as PPO and PPL. The LLL level was much higher in our study than that in the Egyptian samples (16.6\%) (ELMallah et al., 2003), but was close to that of milk thistle seed oil from Czech Republic (24.5\%) (HoLČAPEK et al., 2003). The differences among these studies could be explained by different growing conditions and genotypes. ANDRIKOPOULOS and co-workers (2004) reported more important amount of LLL, which was $46 \%$ for milk thistle oil analysed by HPLC and $36.9 \%$ for the same oil analysed by GC. The determination of these molecular species of TAG can be useful for a better identification of different kinds of milk thistle oil.

\begin{tabular}{lcc}
\multicolumn{3}{l}{ Table 2. Triacylglycerol composition (\%) of oil extracted from milk thistle seeds grown in Tunisia } \\
\hline TAG type & ECN & $\%$ \\
\hline LLLn & 40 & $0.10 \pm 0.1$ \\
OLnLn & 40 & $0.25 \pm 0.1$ \\
LLL & 42 & $22.30 \pm 0.4$ \\
OLLn & 42 & $0.44 \pm 0.2$ \\
LLnP & 42 & $0.07 \pm 0.1$ \\
LLO & 44 & $20.44 \pm 0.3$ \\
LLP & 44 & $17.31 \pm 0.5$ \\
LOO+SLL & 46 & $7.90 \pm 0.2$ \\
OLP & 46 & $14.30 \pm 0.2$ \\
PLP & 46 & $3.11 \pm 0.2$ \\
OOO+SLO & 48 & $1.42 \pm 0.1$ \\
OOP & 48 & $6.91 \pm 0.4$ \\
POP & 48 & $1.74 \pm 0.2$ \\
SOO & 50 & $1.24 \pm 0.1$ \\
SOP & 50 & $2.19 \pm 0.2$ \\
SOS+SSP & 52 & $0.2 \pm 0.2$ \\
SSS & 54 & $0.08 \pm 0.1$ \\
\hline
\end{tabular}

L: linoleic acid; Ln: linolenic acid; O: oleic acid; P: palmitic acid; S: stearic acid.

ECN: equivalent carbon number defined as the total carbon number $(\mathrm{CN})$ in all acyl chains minus twice the double bonds (DB), i.e. $\mathrm{ECN}=\mathrm{CN}-2 \mathrm{DB}$

The TAG composition of milk thistle oil was different than that of olive oil where OLL (4\%) and LLL (1\%) were the minor compounds, and OOO (37\%) and POO (23\%) were the major forms (RĚZANKA \& RĚZANKOVÁ, 1999). Consequently, the amounts of triglycerides 
OOO, POO, OLL, and LLL make possible to differentiate milk thistle oil from olive oil. In the same way, with the levels of triglyceride OLLn and LLLn, it is possible to differentiate the milk thistle oil from the soybean oil. In fact, the levels of OLnLn $(0.25 \%)$ and LLLn $(0.1 \%)$ in the milk thistle oil were much lower than those in the soybean oil $(6.2 \%$ and $10.3 \%$ ) (HoLČAPEK et al., 2003). Generally it can be concluded that milk thistle seed oil has a characteristic TAG pattern as compared with these elucidated for olive oil and soybean oil. On the other side, the major forms of dent corn oil, LLL (23\%), OLL (21\%), OOL (11\%), POL (10\%), and PLL (16\%), are similar in quantity to those present in the milk thistle oil (HARRABI et al., 2008). These five TAGs are also detected in sunflower oil as the major forms of TAGs but in different proportions (HOLČAPEK et al., 2003).

\section{Conclusions}

In summary, this study indicated that milk thistle seeds have high oil content and therefore could be exploited as a natural source of edible oil. Milk thistle oil is a rich source of unsaturated fatty acids with potential beneficial therapeutic activities. This study provides an informative lipid profile that will serve as a basis for further chemical investigations and nutritional evaluation of the milk thistle seeds and their oil.

The authors wish to express thanks to Faculty of Medicine, University of Tunis for presenting facilities that made this work successful.

\section{References}

Andrikopoulos, N.K., Chiou, A. \& Mylona, A. (2004): Triacylglycerol species of less common edible vegetable oils. Food Rev. Int., 220, 389-405.

Baylin, A., Siles, X., Donovan-Palmer, A., Fernandez, X. \& Campos, H. (2007): Fatty acid composition of Costa Rican foods including trans fatty acid content. J. Food Compos. Anal., 20, 182-192.

CALDER, P.C. (2008): Polyunsaturated fatty acids, inflammatory processes and inflammatory bowel diseases. Mol. Nutr. Food Res., 52, 885-897.

El-Mallah, M.H., El-Shami, S.M. \& Hassanein, M.M. (2003): Detailed studies on some lipids of Silybum marianum (L) seed oil. Grasas Aceites, 54, 397-402.

Fathi-Achachlouei, B. \& Azadmard-Damirchi, S. (2009): Milk thistle seed oil constituents from different varieties grown in Iran. J. Am. Oil Chem. Soc., 86, 643-649.

Garaev, E.A., Movsumov, I.S. \& Gazizov, F.Y. (2010): Neutral lipids from Silybum marianum seeds. Chem. Nat. Compd., 46, 629-630

Gerber, M. (1997): Olive oil, monounsaturated fatty acids and cancer. Cancer Lett., 114, 91-92.

Hadolin, M., Skerget, M., Knez, Z. \& Bauman, D. (2001): High pressure extraction of vitamin E-rich oil from Silybum marianum. Food Chem., 74, 355-364.

Harrabi, S., Boukhchina, S., Kallel, H. \& Mayer, P.M. (2009): Fatty acid accumulation in the different fractions of the developing corn kernel. Food Chem., 117, 432-437.

Harrabi S., Boukhchina, S., Kallel, H. \& Mayer, P.M. (2008): An electrospray-ionization mass spectrometry analysis of triacylglycerol in developing corn kernels. Can. J. Anal. Sci. Spectr., 53 (1), $22-27$.

Hasanloo, T., Bahmanei, M., Sepehrifar, R. \& Kalantari, F. (2008): Determination of tocopherols and fatty acids in seeds of Silybum marianum (L.) Gaerth. J. Med. Plants, 7 (4), 69-75.

HolČAPEK, M., JANDERA, P., ZderadičKa, P. \& Hruba, L. (2003): Characterization of triacylglycerol and diacylglycerol composition of plant oils using high-performance liquid chromatography-atmospheric pressure chemical ionization mass spectrometry. J. Chromatog. A., 1010, 195-215. 
IOC (2001): Determination of trans unsaturated fatty acids by capillary column gas chromatography. International Olive Council, COI/T.20/Doc.no.17/Rev.1

IOC (2008): Determination of the difference between actual and theoretical content of triacylglycerols with ECN 42. International Olive Council, COI/T.20/Doc. no. 20 /Rev. 2

Karkanis, A., Bilalis, D. \& Efthimiadou, A. (2011): Cultivation of milk thistle (Silybum marianum L. Gaertn.), a medicinal weed. Ind. Crop. Prod., 34, 825-830.

Khan, I., Khattak, H.U., Ullah, I. \& Bangash, F.K. (2007): Study of the physicochemical properties of Silybum marianum seed oil. J. Chem. Soc. Pak., 29, 545-548.

KinseLLA, J.E. (1986): Food component with potential benefits: the $n-3$ polyunsaturated fatty acids of fish oils. Food Technol., 40 (2), 89-97.

Lechevallier, D. (1966): Les lipids des Lemnacées, analyse des acides gras des lipides des frondes de Spirodela polyrhiza. Compt. Rend. Acad. Sci., 263, 1848-1852.

Malekzadeh, M., Mirmazloum, S.I., Anguorani, H.R., Mortazavi, S.N. \& Panahi, M. (2011): The physicochemical properties and oil constituents of milk thistle (Silybum marianum Gaertn. cv. Budakalászi) under drought stress. J. Med. Plants Res., 5, 1485-1488.

Matthaus, B. \& Ozcan, M.M. (2006): Quantitation of fatty acids, sterols, and tocopherols in turpentine (Pistacia terebinthus Chia) growing wild in Turkey. J. Agric. Food Chem., 54, 7667-7671.

Metcalfe, L.D., Schmitz, A.A. \& Pellka, J.R. (1966): Rapid preparation of fatty acids esters from lipids for gaschromatographic analysis. Anal. Chem., 38, 514-515.

RězANKA, T. \& RĔZANKOVÁ, H. (1999): Characterization of fatty acids and triacylglycerols in vegetable oils by gas chromatography and statistical analysis. Anal. Chim. Acta, 398, 253-261.

RŮŽIČKovÁ, G., FoJTovÁ, J. \& SoučKovÁ, M. (2011): Výnos a kvalita oleje plodů ostropestřce mariánského (Silybum marianum (L.)) z pohledu prostředí a genotypu - pilotní studie (The yield and quality of milk thistle (Silybum marianum (L). Gaertn.) seed oil from the perspective of environment and genotype - a pilot study). Acta Fytotechnica et Zootechnica, 1, 9-12.

Velasco, L., Rojas-Barros, P. \& Fernandez-Martinez, J.M. (2005): Fatty acid and tocopherol accumulation in the seeds of a high oleic acid castor mutant. Ind. Crop. Prod., 22, 201-206. 